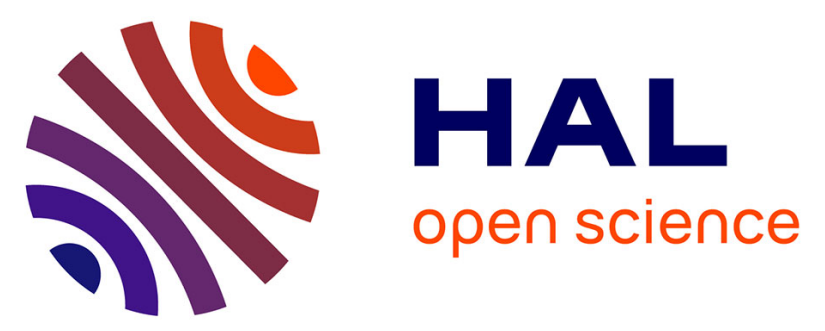

\title{
Dual beam infrared thermal lens spectrometry at 965 cm-l absorption band as a measure of nonconjugated trans fatty acids content in margarine samples
}

\author{
M. Franko, D. Bicanic, P. van de Bovenkamp
}

\section{- To cite this version:}

M. Franko, D. Bicanic, P. van de Bovenkamp. Dual beam infrared thermal lens spectrometry at 965 cm-l absorption band as a measure of nonconjugated trans fatty acids content in margarine samples. Journal de Physique IV Proceedings, 1994, 04 (C7), pp.C7-479-C7-482. 10.1051/jp4:19947112 . jpa00253165

\section{HAL Id: jpa-00253165 \\ https://hal.science/jpa-00253165}

Submitted on 1 Jan 1994

HAL is a multi-disciplinary open access archive for the deposit and dissemination of scientific research documents, whether they are published or not. The documents may come from teaching and research institutions in France or abroad, or from public or private research centers.
L'archive ouverte pluridisciplinaire HAL, est destinée au dépôt et à la diffusion de documents scientifiques de niveau recherche, publiés ou non, émanant des établissements d'enseignement et de recherche français ou étrangers, des laboratoires publics ou privés. 


\title{
Dual beam infrared thermal lens spectrometry at $965 \mathrm{~cm}^{-1}$ absorption band as a measure of nonconjugated trans fatty acids content in margarine samples
}

\author{
M. Franko, D. Bicanic* and P. van de Bovenkamp** \\ Jozef Stefan Institute, Department of Environmental and Analytical Chemistry, Jamova 39, \\ 61111 Ljubljana, Slovenia \\ * Laser Photoacoustic Laboratory, Department of Agricultural Engineering and Physics, Agricultural \\ University, Bomenweg 4, 6703 HD Wageningen, The Netherlands \\ ** Department of Human Nutrition, Biotechnion, Agricultural University, Bomenweg 2, \\ 6703 HD Wageningen, The Netherlands
}

\begin{abstract}
Dual beam thermal lens spectrometry was applied (at $965 \mathrm{~cm}^{-1}$ ) for the first time to determine the content of trans unsaturated fatty acids in margarine. An improvement in sensitivity ( $\mathrm{LOD}=0.002 \%$ ) of more than two orders of magnitude in comparison with traditional infrared technique was achieved.
\end{abstract}

\section{INTRODUCTION}

Animal fats and vegetable oils are vital ingredients of a balanced diet because they supply bodily warmth and build physical energy. Triglycerides (esters of glycerol and three fatty acids (FA)) are major constituents of oils and fats. In addition, small amount of free fatty acids (FFA), partial glycerides and some non-glyceride constituents are always found. It is a character of $\mathrm{CH}_{3}\left(\mathrm{CH}_{2}\right)_{\mathrm{n}}$ group (R) that enables one to discriminate between various FA. In saturated FA represented by $\mathrm{CH}_{3}\left(\mathrm{CH}_{2}\right)_{\mathrm{n}}$ $\mathrm{CO}_{2} \mathrm{H}, \mathrm{R}$ is a simple paraffin chain and FA are classified according to a number $\mathbf{n}$ of carbon atoms in the chain. In naturally occuring FA integer $n$ takes even values $2<\mathrm{n}<24$; palmitic (C16:0) and stearic (C18:0) FA are most abundant in plant and animal life.

In FA from natural vegetable oils and fats, double bonds are overwhelmingly in cis configuration and are not conjugated with other double bonds. The most widely abundant of all FA is oleic acid (cis-9, octadecenoic acid, C18:1, 9c) having only one double bond in the mid $(9,10)$ position i.e. $\mathrm{CH}_{3}\left(\mathrm{CH}_{27} \mathrm{CH}=\mathrm{CH}\left(\mathrm{CH}_{2}\right)_{7} \mathrm{COOH}\right.$. The corresponding trans counterpart is elaidic acid (18:1, $\left.9 \mathrm{t}\right)$; its trace amounts are normally found only in some animal species. Freshly refined vegetable oils normally have trans FA content below $1 \%$ (before hydrogenation) compared to 5 to $8 \%$ for naturally harder beef fat [1]. Trans FA content in hydrogenated margarine oil ranges from 4 to $42 \%$. During process of (partial) hydrogenation used to give oil some consistency, melting point of oil changes but at a same time cis to trans inversion and migration of double bonds take place.

The degree of unsaturation of an edible oil is an important criterion of its suitability as a food product. In recent years saturated fats were implicated as contributory causes of cardio-vascular diseases. It has been suggested that a total fat intake in a normal diet should be lowered mainly by reducing amount of saturated fat intake. Furthermore, trans FA must be included with the saturated FA for purposes of nutritional labelling because of their comparable biological effects [1]. It is therefore important to determine content of trans isomers in samples of food products. Current methods for 
analysis of oils and fats are based on infrared (IR) transmission spectroscopy and gas chromatography (GC).

Isolated trans bonds in long chain unsaturated FA, esters and glycerides show specific absorption band [2] centered at approximately 10.3 microns $\left(965 \mathrm{~cm}^{-1}\right)$. The IR transmission method is widely used for quantitative determination of nonconjugated trans FA in fats and oils in the presence of cis and saturated FA [3]. In case of a low trans FA content, fat (or oil) is first converted into fatty acid methyl esters (FAME) according to IUPAC method [1]. The trans content of oil is then calculated from the amount of methyl ester derived from the calibration curve. The spectrometer is usually calibrated with methyl elaidate, trieladine or elaidic acid; this latest $(\mathrm{C} 18: 1, \mathrm{t})$ is the geometrical isomer of cis oleic acid which in turn is present in nearly all naturally occurring fats.

Despite progress made in the field of GC, problem of fully separating geometrical isomers in a heterogeneous mixture of positional and geometrical isomers is not resolved yet. Zharov et al. [4] have combined $\mathrm{GC}$ and a concept of $\mathrm{CO}_{2}$ laser optothermal spectroscopy to perform selective analysis of geometrical isomers in a FAME mixture.

The objective of the work described here was to apply thermal lens spectrometry (TLS) for a direct determination of trans FA in liquid samples. TLS is known for its high sensitivity when measuring weak absorbances in condensed phase samples [5]. The main goal of this work was to explore the potential of IR dual beam TLS for determination of low amounts of isolated trans unsaturated FA in margarine and to compare the sensitivity to that obtainable by generally accepted IR method.

\section{EXPERIMENTAL}

The thermal lens spectrometer (Fig.1) consisted of a in house made $\mathrm{CO}_{2}$ laser tuned to $10 \mathrm{R}(8)$ emission line. The excitation beam was divided at the beam splitter (BS) and its wavelength monitored by spectrum analyzer (SA). The power of the laser beam transmitted through two iris diaphragms (D1 and D2) was reduced to $50 \mathrm{~mW}$ at the position of sample cell (SC) by means of two mesh attenuators (MF1 and MF2). The laser beam was focused into the sample cell (Fig. 2) by a ZnSe lens L (f $=254$ $\mathrm{mm}$ ) and modulated $(45 \mathrm{~Hz})$ by a mechanical chopper $(\mathrm{CH})$. The laser power was monitored by a pyrodetector (Py) connected to a lock-in amplifier (LT1) which output was fed to a digital voltmeter (DMM3). The periodical heating of the sample was sensed by an unfocussed probe beam (He-Ne laser, $10 \mathrm{~mW}$ ) which intensity was measured with a photodiode (PD) having an area of $1 \mathrm{~mm}^{2}$ and placed behind the pinhole (PH). Positions of the two beams could be regulated by a set of five adjustable plane mirrors (M1-M5). Thermal lens signals, i.e. changes in the probe beam intensity were monitored by the diode, were fed to lock-in amplifier (LT2) and read from a digital multimeter (DMM1). Relative signals were obtained after normalization to the average value of the probe beam at its axis (which was read from a second digital multimeter (DMM2) connected in parallel with the lock-in amplifier). Calibration curves were obtained by measuring TL signals in solutions of methyl elaidate (9toctadecenoic acid methyl ester) in carbondisulfide $\left(\mathrm{CS}_{2}\right)$ in a 0.06 to $0.6 \%$ concentration range. Samples of margarine were dried prior to a disolution in $\mathrm{CS}_{2}$ by melting and discarding water fraction after centrifugation. Solutions were introduced into the cell (Fig. 3) using a microsyringe; a $250 \mu \mathrm{m}$ thick teflon spacer defined a cell length. 


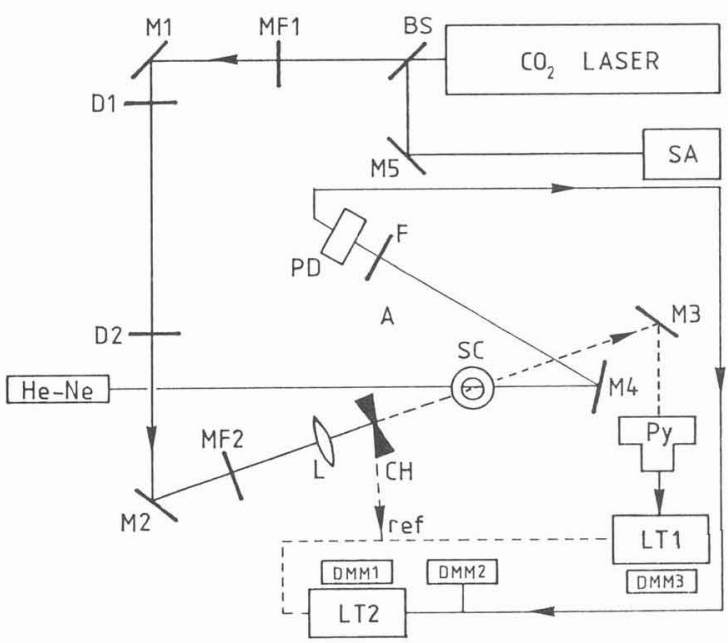

Fig. 1 Dual beam infrared thermal lens spectrometer.

\section{RESULTS}

The calibration curve obtained with a TL spectrometer described above is shown in Fig. 3. It demonstrates a good linearity $(\mathrm{R}=0.998)$ over wide concentration range. Based on the slope of the calibration curve and the signal to noise ratio of 3 , a detection limit of $0.002 \%$ of methyl elaidate in $\mathrm{CS}_{2}$ was calculated. The performance of $\mathrm{TL}$ technique was tested by analyzing three commercial margarine brands having different trans isomer contents. Sample 1 contained vegetable oil and substantial fraction of a hydrogenated animal fat. Sample 2 was a partially hydrogenated vegetable fat while margarine 3 (low trans FA content) is a dietetic product containing nonhydrogenated vegetable fat. Samples of dried margarine (10-100 mg) were dissolved in about $3 \mathrm{ml}$ of $\mathrm{CS}_{2}$ and injected into the sample cell. The results are summarized in Table 1. For trans monounsaturated FA 1 equ. $=1$ mole. Therefore, assuming that trans unsaturated FA are predominantly present as $\mathrm{C} 18: 1$ and $\mathrm{C16:1}$ acids the values in the last column of Table 1 are calculated. Lacking the knowledge about the true C18:1/C16:1 ratio can result in an error not exceeding $5 \%$ (calculated on basis of molecular weights of C18:1 and C16:1 FA). In order to obtain values for pure samples, water content in margarine (about 15\%) has to be taken in account.

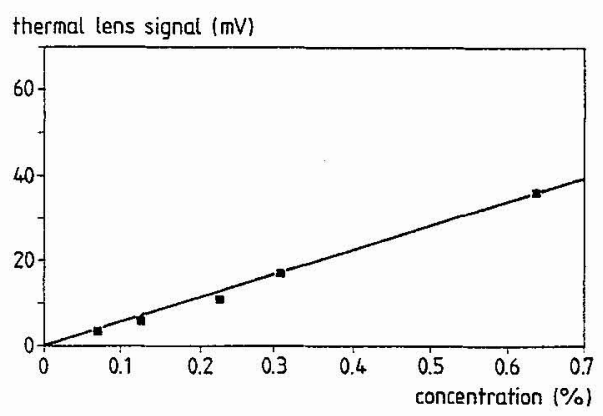

Fig. 3. Calibration curve displaying the magnitude of the thermal lens signal $(\mathrm{mV})$ as a function of percentual concentration of methyl elaidate in carbondisulphide. 
Table 1. Content of trans unsaturated FA in margarine samples as determined by thermal lens spectrometry (results are calculated for dried samples).

\begin{tabular}{|c|c|c|}
\hline Margarine & $\begin{array}{c}\text { Equivalents of trans } \\
\text { double bonds/g sample }\end{array}$ & $\begin{array}{c}\% \text { trans unsaturated FA } \\
(\mathrm{C} 16: 1+\mathrm{C} 18: 1)\end{array}$ \\
\hline \hline sample 1 & $(7.4 \pm 0.1) \times 10^{-4}$ & $19.9 \pm 0.3$ \\
\hline sample 2 & $(2.2 \pm 0.2) \times 10^{-4}$ & $6.0 \pm 0.6$ \\
\hline sample 3 & $(2.51 \pm 0.03) \times 10^{-4}$ & $6.8 \pm 0.2$ \\
\hline
\end{tabular}

\section{CONCLUSIONS}

Thermal lens spectrometry was shown useful for quantitative measurements of trans isomers in oils and fats. The sensitivity for trans FA determination in $\mathrm{CS}_{2}$ solution is significantly improved by measuring absorbance via TL effect. Considering few tenth of percent as a detection limit for IR transmission measurement [5], an improvement of over two orders of magnitude was achieved; this value agrees well with expected value 220 for enhancement factor $\mathrm{E}$ of $\mathrm{TL}$ method calculated from known values [6] for thermo-optical properties of $\mathrm{CS}_{2}$ (thermal conductivity $\mathrm{k}$ and temperature coefficient of refractive index $\mathrm{dn} / \mathrm{dT}$ ) assuming $50 \mathrm{~mW}$ of laser power $P$ at wavelength $\lambda$ of the probe beam $(632 \mathrm{~nm})$ and using expression $E=[0.52 \mathrm{P}(\mathrm{dn} / \mathrm{dT})] / \lambda \mathrm{k}$. Results obtained with realistic samples show a good agreement with those available from GC measurements, although direct comparison cannot be made since the analysis of total amount of FA was not carried out. Thermal lensing method (alone or in a combination with GC) may eventually advance to a stage at which several other analytical applications in the field of fats and oils would become feasible. These include monitoring of oil and fat's properties such as degree of unsaturation, polymorphic forms and oxidative stability.

Acknowledgments: One of authors (M.F.) expresses his gratitude to Dutch Organisation for Scientific Research NWO, The Hague for granting a Visiting Scientist fellowship. Credit is also to Unilever Research Laboratory, Vlaardingen, The Netherlands and to European Community for received support. Skilled work of Mees Schimmel and Kees Rijpma and laboratory assistance of Jannie Bos and Truus Kosmeijer-Schuil from Wageningen Agricultural University are gladly acknowledged.

\section{REFERENCES}

[1] Kochar S.P., Rossell J.B., Intern. Scient. 5 (1987), 23-32.

[2] Helrich K. (Ed.), Official methods of analyses of the association of Official Analytical Chemists AOAC, Volume 2, $15^{\text {th }}$ edition, AOAC Inc., Arlington, Virginia (1990) pp. 969-970.

[3] Matissek R., Schnepel F.M., Steiner G., Lebensmittel analytik $2^{\mathrm{e}}$ Auflage, Springer Verlag, Berlin (1992) pp 70-72.

[4] Zharov V.P., Lethokov V.S., Montanari S.G. and Tumanova L.M., Jour. of Molec. Struc. 115 (1984) 261-270.

[5] Egan H., Kirk S., Sawyer R., Pearson chemical analysis of foods, $8^{\text {th }}$ edition, Churchill Livingstone, London (1981) pp 507-545.

[6] Dovichi N.J., Crit. Revs. in Anal. Chem. 17 (1987) 357-343. 